REVISTA DE GESTÃO E SECRETARIADO

MANAGEMENT AND ADMINISTRATIVE

PROFESSIONAL REVIEW

ISSN: 2178-9010
Revista GeSec

São Paulo, SP, Brasil

11(2), p. 139-163

maio/ago. 2020

DOI: http://dx.doi.org/10.7769/gesec.v11i2.970

\title{
Mapas cognitivos de identidade da experiência de declínio organizacional
}

\author{
Identity cognitive maps of the organizational decline experience
}

\author{
Eveli Freire de Vasconcelos ${ }^{1}$ \\ Antonio Virgilio Bittencourt Bastos ${ }^{2}$ \\ Maria Eduarda Avancini Casali ${ }^{3}$
}

\section{Resumo}

O texto a seguir, elege como foco de interesse central o mapeamento dos elementos constituintes do esquema cognitivo de trabalhadores sobre o fenômeno de declínio organizacional vivido em um projeto organizacional de grande porte. A área teórica deste estudo delineou-se pela Ciência Cognitiva, apresentando como conceito operacional principal a teoria do esquema cognitivo, permitindo, assim, discutir as estruturas de conhecimento dos trabalhadores em relação a um elemento de sua realidade. Dessa forma, explorar por meio de entrevista, realizar a análise de conteúdo e descrever a maneira como esses sujeitos concebem e explicam a experiência de declínio organizacional é o que nos remete à investigação da complexidade que pode existir entre as perspectivas individuais e grupais, interfaceadas pela perspectiva organizacional. Os relatos revelam que o insucesso (declínio) do projeto organizacional vai além da dimensão financeira e integra questões políticas, sociais e morais, relacionando o fenômeno predominantemente aos fatores macroambientais. Foi possível, identificar que os esquemas explorados se mostraram úteis para a compreensão do significado da experiência em uma organização que entrou em declínio A título de conclusão, permite-se pensar o trabalhador em tempos de crise, a possibilidade de observação de diferentes articulações contextuais, que podem fortalecer ou fragilizar a saúde psicossocial dos atores e das organizações de trabalho especialmente frente à real ameaça de desemprego presente durante a ocorrência de declínio.

Palavras-chaves: Declínio Organizacional. Esquema cognitivo. Mapa cognitivo de identidade. UFN III.

\footnotetext{
Abstract

The following text, elects as a focus of central interest the mapping of the constituent elements of the cognitive schema of workers about the phenomenon of organizational decline lived in a large organizational project. The theoretical area of this study is outlined by cognitive science, featuring the main concept of cognitive schema theory, thus allow discuss the knowledge structures of workers relative to an element of your reality. Therefore, exploit by means of interview, performing content analysis and describe the way these guys conceive and explain the organizational decline experience is what brings us to research the complexity that may exist between the individual and group

${ }^{1}$ Doutora em Psicologia, Docente nos cursos de Pós-graduação Lato Sensu em Psicologia Organizacional e do Trabalho, Avaliação e Perícia Psicológica e de Psiquiatria e Saúde Mental com Enfase em Humanidades Médicas da Universidade Católica Dom Bosco (UCDB).

2 Doutor em Psicologia, Docente na Universidade Federal da Bahia (UFBA), Coordenador da Área de Psicologia da Coordenação de Aperfeiçoamento de Pessoal do Nível Superior (CAPES), Pesquisador I-A do Conselho Nacional de Desenvolvimento Científico e Tecnológico (CNPq).

${ }^{3}$ Graduanda em Psicologia na UCDB.
} 
perspectives, interfaceadas by the organizational perspective. The reports reveal that the failure (decline) of the organizational project goes beyond the financial dimension and integrates political, social and moral issues, linking the phenomenon predominantly to macroenvironmental factors. It was possible to identify that the schemes analyzed were useful for understanding the meaning of the experience in an organization that has entered into decline. In conclusion, it was possible to understand the worker in times of crisis and the possibility of observe different contextual articulations, which can strengthen or weaken the psychosocial health of actors and work organizations especially in the face of the real threat of unemployment present during the occurrence of decline.

Keywords: Organizational decline. Cognitive schema. Cognitive map of identify. UFN III.

\section{Introdução}

Esta pesquisa buscou mapear os elementos constitutivos do esquema cognitivo associado à experiência de declínio no projeto UFN III. Este projeto foi apresentado inicialmente como uma grande solução para o país, pertencente ao Programa de Aceleração do Crescimento (PAC), o qual foi criado para retomar o planejamento e a execução de grandes obras que contribuíssem para o desenvolvimento sustentável do Brasil, com foco em infraestrutura social, urbana, logística e energética. O projeto tinha como órgão responsável o Ministério de Minas e Energia (MME) e como executor a Petrobrás e foi citado no Programa de Mobilização da Indústria Nacional de Petróleo e Gás (PROMINP) como um dos principais empreendimentos do país, sendo o único de toda a Região Centro-Oeste. Seu declínio constituiu-se em uma situação de adversidade, afetando de modo especial a cidade de Três Lagoas, o Estado de Mato Grosso do Sul e a todos os seus trabalhadores.

A morte da organização em questão (projeto organizacional UFN III), ocorrida em estágio inicial (construção), pode estar diretamente relacionada à ausência de recursos financeiros. Sem dúvida, essa questão contribui com o declínio, mas as variáveis macroambientais parecem ter grande contribuição. Serra, Ferreira e Madeira (2013) discutem que as pesquisas sobre declínio buscam compreender como e por que as empresas falham ou perdem a competitividade, argumentando que o interesse dos pesquisadores ainda mantém atenção na conceituação teórica, em como ocorre, nas suas consequências e atributos, além de caracteristicamente serem longitudinais. Por outro lado, no estudo com a UFN III, percebe-se que aquele estágio de nascimento, que deveria marcar o início do desenvolvimento organizacional de um grande empreendimento, acabou por demarcar a fase de declínio. Período este em que os membros da organização tendem a modificar seus objetivos e expectativas. Para Lester, Parnell e Carraher (2003), os membros da organização tornam-se mais preocupados com os objetivos pessoais do que com os objetivos organizacionais situação compreensível diante da ameaça de desemprego. Percebe-se que pouco foi

Revista de Gestão e Secretariado (GeSec), São Paulo, SP, 11(2), maio/ago., 2020, p. 139-163. 
pesquisado empiricamente tendo o trabalhador como unidade de análise durante esses eventos de crise, especialmente no Brasil.

O trabalho elaborado por estudo de Serra et al. (2013) encontram evidências de que os principais pontos relacionados ao declínio organizacional surgem com a combinação dos seguintes temas: a tomada de decisão frente às mudanças e a tomada de decisão diante da necessidade de adaptação às mudanças externas. As bases que articulam as redes geradoras de decisão são a percepção e a sensação; os atos, dentro de um contexto singular, são percebidos, interpretados e as decisões construídas (Bastos, 2001).

Nas teorias contemporâneas, como as de base Cognitiva, o ambiente se sobressai, sinalizando à organização um conjunto de dimensões abstratas cujas ideias ocupam um espaço importante e se estendem à definição de estratégias, que é uma forma de ajustar a relação entre a organização e seu meio ambiente (Fonseca \& Machado-Da-Silva, 2010).

Fonseca e Machado-da-Silva (2010, p. 65) apontam a necessidade de se considerar o universo cognitivo como "reserva localizada de conhecimento e artefatos simbólicos com significados intersubjetivamente compartilhados e mobilizados por atores em interação", sendo o sujeito um agente psicossocial que desempenha um papel fundamental na formulação da realidade, por meio das percepções e interpretações compartilhadas (Souza, 2007).

As mudanças socioeconômicas, políticas e tecnológicas das últimas duas décadas, apontadas por Hodgkinson e Healey (2008), influenciaram o crescimento do interesse pelos estudos cognitivos nas organizações modernas e as levaram a avançar na compreensão das potencialidades e limitações cognitivas de seus gestores e atores. Esse aspecto é reforçado por Bastos, Loiola, Queiroz e Silva (2014), ao ressaltar os indivíduos e suas interações como estruturas das organizações. Para esses autores, os estudos na área são conduzidos pela ideia de que a forma pela qual os indivíduos organizam e processam o seu pensamento influencia a ação individual e a partilha desse pensamento/ação entre os membros da organização gera o que se chama de comportamento organizacional.

Moscon (2009, p. 50) reafirma "o interesse e desenvolvimento da ciência cognitiva e relaciona a retomada da ênfase nos recursos internos nas organizações, associada às suas características subjetivas e natureza socialmente construída”. Novas experiências, assim como as mudanças do contexto e consequente transformações organizacionais, surgem e nos remetem a questões como: algumas organizações com histórico sólido no país apresentam necessidades drásticas de mudança de paradigma e de rompimento de modelos estratégicos de decisão. As mudanças de reorientação se iniciam no período de crise e são as mais arriscadas. As mudanças geralmente são iniciativas de sucesso, mas podem também fracassar. E quando 
isso ocorre? Tem-se como recomendável interrogar os atores em relação às suas experiência (Açuanã \& Fernandes, 1995).

Esforços de pesquisa devem ser feitos para entender, ainda, as diferenças que podem surgir no significado e interpretações dos atores frente a distintas experiências de fracasso, decadência ou declínio organizacional, assim como à situação de recolocação no mercado ou de desemprego. Bastos, Souza, Costa e Peixoto (2011) definem como embrionárias também as pesquisas acerca da associação entre estrutura cognitiva de trabalhadores e diferentes estágios organizacionais, ainda que, para Bastos e Santos (2000), compreender as estruturas cognitivas utilizadas pelos indivíduos sobre trabalho qualificado e empresa moderna sejam imprescindíveis, pois os esquemas estudados são úteis para explorar a identidade dos trabalhadores e para conhecer como lidam com e como dão significado às transformações e mudanças do mundo do trabalho e das organizações. Moscon $(2009$, p. 55) discute que:

[...] em qualquer percepção, as nossas expectativas acerca do percebido alteram a forma como o enxergamos e influenciam neste processo de categorização. Os esquemas seriam, portanto estruturas mentais que contém essas expectativas e conhecimento do mundo (eventos, papéis sociais, pessoas, fatos, etc.) que nos auxiliam no processo de selecionar e processar as informações recebidas no contexto social.

Pode-se dizer que a consequência imediata dessa revisão é evidenciar essa mudança de cenário que se manifesta na economia do país e que, consequentemente, repercute no mundo do trabalho, impondo discussões como, por exemplo, a respeito do declínio organizacional. Existe uma impressão geral de que o panorama que assola o Brasil atualmente permaneça pelos próximos anos, sendo necessário considerar que as OT enfrentam e enfrentarão as incertezas do ambiente externo de forma contundente.

Sendo assim, surge a segunda consequência: demonstrar os desafios impostos aos atores organizacionais, estimando limites cognitivos das decisões e ações. Tais questões precisam ser tomadas como alvo de atenção, visto que podem ampliar o risco de declínio organizacional, assim como impactos psicossociais significativos ao trabalhor.

E como terceira consequência desponta a visão geral de como a abordagem cognitiva vem sendo utilizada no contexto organizacional, evidenciando valioso repertório teórico para produção de conhecimento. Esse material também fornece um referencial à leitura do caso da UFN III, organização escolhida para este estudo por critérios como sua importância para o Brasil e para o estado de Mato Grosso do sul, além da expectativa de desenvolvimento para a cidade de Três Lagoas; porém, a paralização definitiva das atividades no ano de 2015 ocasionou vários impactos sociais, econômicos e financeiros, remetendo-nos à identificação de como os atores concebem os desafios impostos pelo declínio organizacional daquele que 
seria um dos maiores investimentos realizados pelo Governo Federal no Estado do Mato Grosso do Sul, tomando como alvo os esquemas cognitivos .

Essa realidade reforça a percepção de que as linhas que demarcam alguns pontos de análise sobre a situação atual das organizações e de seus trabalhadores precisam ser reconhecidas. A economia em transição provoca efeitos complexos e significativos sobre as empresas; como consequência, as forças mais importantes desse contexto irão interagir e confrontar as variáveis de base (socioeconômica e política) e formar esquemas que orientam o comportamento do indivíduo.

\section{Metódo}

Caracteriza-se como um estudo de casos, por ser uma investigação empírica de um fenômeno contemporâneo dentro de seu contexto. Mesmo com estudo de casos, ou de multicascos, vale destacar que não se busca generalizar os resultados de pesquisa. Segundo Gil (1987), o estudo de dois ou mais casos não traz em si a afirmação da representatividade do universo de trabalhadores da UFN III, mas, sim, de maior abrangência dos resultados (Salles, 2015).

A UFN III, como empreendimento de relevância nacional, atraiu trabalhadores de outras cidades de Mato Grosso do Sul, como também mão de obra migratória de outros Estados. Com a dissolução do projeto organizacional, muitos trabalhadores voltaram às suas cidades de origem e o convite para a participação nesta pesquisa precisou adaptar-se a essa situação, de modo a definir a realização da pesquisa por e-mail e/ou redes sociais, além da possibilidade da entrevista presencial.

No contexto contemporâneo, as redes sociais podem ser um recurso eficaz de acesso aos participantes de uma investigação. Segundo Breakwell et al. (2010), as pesquisas por $e$ mail já são usualmente utilizadas com questionários e planos de entrevistas.Esse desenvolvimento de pesquisas pela internet está diretamente relacionado ao fato de propiciar o aumento do capital social das pessoas, agregando contato com amigos e parentes que vivem nas proximidades e/ou mais distantes (Wellaman, 2001).

Segundo Wildman, Salas e Scott (2013), quando se pretende pesquisar cognição, a primeira decisão refere-se à abordagem utilizada para reunir os dados que serão avaliados. Algumas pesquisas têm estudado cognição usando dados textuais qualitativos como fonte geralmente, entrevistas individuais ou em grupos focais com os membros das equipes, são 
transcritas ou inquéritos abertos são usados para recolher dados textuais em relação ao desempenho passado.

Neste caso, a entrevista foi semi -estruturada, os procedimentos da entrevista constavam de: apresentação do Termo de Consentimento Livre e Esclarecido, preenchimento do questionário pelo participante e revisão das respostas (momento em que a pesquisadora revisava junto ao mesmo as respostas às perguntas da entrevista). A entrevista realizada fora do episódio vivido é a principal vantagem para provocação do conteúdo de cognição dos atores, assim como de uma equipe (Wildman et al., 2013).

Em uma situação aparentemente tão diferenciada, os esquemas desenvolvidos têm poder de moldar as reações. Sabe-se que a forma como os atores estruturam seu conhecimento sobre a realidade irá influenciar seu comportamento, mas ainda é escassa a compreensão sobre a dinâmica intrínseca desses processos internos, principalmente que venham empiricamente esclarecer aquilo que já está consolidado (Bastos \& Janisseck, 2014).

Com base na análise de conteúdo dos dados e na metodologia de mapeamento cognitivo, explora-se o significado atribuído à experiência e representa-se por um esquema gráfico; em seguida, um mapa de identidade de cada indivíduo sobre o declínio e um mapa coletivo que evidencie a similaridade dos esquemas quanto aos impactos do fenômeno.

Os mapas cognitivos evidenciam as diferentes características das estruturas de conhecimento de cada um dos atores (Jordão, 1998). A ideia do mapeamento é desenvolver um esquema gráfico dos elementos centrais que surgem quando as pessoas raciocinam sobre uma determinada questão. "O mapeamento cognitivo revela-se, portanto, uma estratégia metodológica especialmente voltada para explicitar os processos de construção de sentido e a estruturação de conhecimento (esquemas) que os guia, [...]" (Souza, 2007, p. 154).

Bastos (2000) discute a função explicativa dos mapas cognitivos, capaz de expor como os indivíduos controem e arranjam suas experiências. Embora as pesquisas cognitivas evidenciem que as pessoas utilizam suas estruturas para dar sentido às informações e assim formam mapas, para Fiol e Huff (1992) esses mapas estão na forma de suposições arraigadas e tomadas como certas, e, portanto, estão escondidos até mesmo de quem os usa; sendo assim, as pesquisas cognitivas que utilizam o mapeamento tentam dar visibilidade às estruturas. "Os mapas cognitivos são representações, schemas ou modelos mentais construídos pelos indivíduos, a partir das suas interações e aprendizagens em um domínio específico do seu ambiente, e que cumprem a função de dar sentido à realidade [...]” (Bastos, 2000, p. 4).

Além disso, os interessados em cognição em contextos organizacionais têm trabalhado para reconhecer as estruturas que são compartilhadas entre os indivíduos. Para Weick e 
Bougon (1986 citado por Bastos, 2002, p. 66), as “organizações existem, largamente, na mente e sua existência toma a forma de mapas cognitivos". O desenho do mapa pode ser pensado como o projeto da mente, que, para a Psicologia, tem como objetivo a compreensão da percepção e cognição humana (Montello, 2002). O mapa cognitivo é a representação do esquema a partir da interação humana em um ambiente específico e "as palavras que os indivíduos enunciam em um dado contexto constituem os blocos para a construção do mapa cognitivo, sendo este construído pelo pesquisador a partir de um discurso enunciado ou escrito pelo indivíduo" (Bastos, 2000, p. 4).

Os mapas utilizados neste trabalho são mapas de identidade, capazes de identificar os blocos conceituais básicos com que os atores trabalham. "Os mapas de identidade são aqueles que assimilam os conceitos dos quais os indivíduos se valem para organizar seu entendimento de um problema ou campo especial" (Fiol \& Huff, 1992 citado por Rios, Lula, Amaral e Bastos, 2009). Apresenta-se um mapa de identidade sobre a temática do declínio organizacional para cada um dos seis casos para discussão. O mapa coletivo identifica categorias e conteúdos relacionados que podem ser agrupados para indicar temas de importância ao grupo; a frequência do uso da palavra é um reflexo da sua centralidade cognitiva e a utilizamos para estruturar o mapa para síntese final da experiência por meio dos elementos em comum que integram a forma dos participantes processarem suas experiências. Esses dados foram organizados sob forma de mapas cognitivos individuais e coletivos, utilizando-se o software MindManager ${ }^{\circledR}$ versão X5 (Mindjet LLC, Califórnia, Estados Unidos) para os mapas individuais e para aquele sobre os impactos do declínio.

O software pode contribuir com a organização e tratamento das informações, mas não dispensa a análise do pesquisador (Leite, 2013 citado por Walter \& Bach, 2015). Recurso que para Cantero (2014) permitem: nomeações, conceituações, segmentações, categorizações e processos de visualização e auxiliam na organização de informações para a análise de conteúdo.

Funcionam como mapas por permitirem ao indivíduo perceber o ambiente numa escala mais ampla, além daquela da percepção imediata. Os mapas cognitivos devem ser vistos, ao mesmo tempo, como conceito e como metodologia. Enquanto conceito, designam o conjunto de elementos e relações que um indivíduo ou grupo utiliza para entendimento de uma dada situação; como metodologia, indicam procedimentos para a representação gráfica de tais elementos e relações (Machado-da-Silva, Fonseca, e Fernandes, 1999, p. 3).

Assim, optou-se por realizar a pesquisa com ex-funcionários da construção da UFN III, independentemente de sua vinculação legal ser ao Cadastro Nacional de Pessoas Jurídicas 
(CNPJ) do consórcio ou a empresa líder do consórcio (Galvão Engenharia), sendo necessário recorrer a técnicas de coleta de informações variadas, envolvendo entrevista semiestruturada e documentos como: publicações do Governo Federal, produção da imprensa, e relatórios e manuais da Galvão Engenharia.

\section{Resultados e Discussão}

\subsection{UFN III}

Tanure, Evans e Pucik (2007) discutem a importância de considerar o contexto em que a organização está inserida. Conhecer a história e a realidade local se faz necessário, visto que no Brasil temos uma grande diversidade sociocultural a ser reconhecida. Esse princípio da influência da cultura local reforça a necessidade de direcionarmos as investigações e ampliarmos os estudos sobre as organizações de trabalho presentes em Mato Grosso do Sul, pois ainda são escassos sob a perspectiva aqui apresentada

Segundo o jornal Campo Grande News (Martins, 2013), de 27 de abril de 2013, foi anunciado em 24 de novembro de 2009, pelo Governo Federal, que seria instalada uma unidade das Unidades de Fertilizantes Nitrogenados em Mato Grosso do Sul e que a escolha do local seria uma compensação ao Estado que não havia sido escolhido como um dos locais para os jogos da Copa do Mundo de 2014.

De acordo com o que está descrito no PAC (Brasil, [2007?]a) sobre o petróleo e gás natural, a prioridade do investimento em petróleo e gás natural em Mato Grosso do Sul é a de consolidar as atividades existentes e ampliar as descobertas do pré-sal. A proposta previa a estruturação da cadeia produtiva da indústria de petróleo, envolvendo “indústrias naval, mecânica, metalúrgica, siderúrgica, química e de engenharia de precisão, entre outras" (Brasil, [2007?]b, primeiro parágrafo, linha 4).

O empreendimento da UFN III tinha como principal característica a tecnologia mais moderna que existe, visando ao alcance da maior produtividade com menor consumo de materiais e de energia, assim como menos emissões atmosféricas e efluentes líquidos. A indústria ocuparia uma área total de aproximadamente $965.000 \mathrm{~m}^{2}$, sendo que a área construída seria de aproximadamente $667.000 \mathrm{~m}^{2}$. Seria basicamente composta por três grandes grupos operacionais: Extra-Muros, On-Site e Off-Site (relatório de impacto ambiental). 
A construção da UFN III foi iniciada em maio de 2012, em termos de operacionalização da obra, basicamente ao que se refere à terraplanagem e à drenagem do terreno. A partir de então, se iniciou a construção estrutural, que incrementou substancialmente o contingente de trabalhadores, a ponto do número de contratados superar as 5.000 pessoas do ano de 2013 (Ribeiro, 2014).

O consórcio formado pelas empresas GDK, Sinopec e Galvão Engenharia estava à frente da edificação da fábrica, de modo que a obra deveria ser concluída em 2014. No entanto, apesar da estrutura e da política adotada pela empresa, os salários começaram a atrasar na UFN III e, como consequência, temos várias manifestações de insatisfação e descontentamento de muitos trabalhadores. Em junho de 2013, foi realizada uma assembleia em frente ao canteiro de obras da fábrica, na qual 6.000 trabalhadores decidiram realizar uma paralisação de 72 horas, de maneira que somente o pessoal administrativo entraria nas dependências. A paralisação foi feita com o objetivo de chamar a atenção do consórcio e da comunidade local para o atraso nos salários, na tentativa de buscar alternativas junto ao consórcio para o recebimento (Vicente, 2013).

Em 19 de dezembro de 2014, o jornal Valor Econômico Online (Pupo, 2014) publicou a rescisão do contrato entre a Petrobras e as empresas responsáveis pela construção da UFN III, deixando a situação ainda mais complexa. A estatal afirmou que o descumprimento do contrato pelo consórcio seria a causa do distrato, e atentou para a inadimplência aos trabalhadores e fornecedores, salientando que já estava tomando medidas legais para que o grupo de empreiteiras cumprisse com seus compromissos (Pupo, 2014). Segundo a matéria publicada, $82 \%$ da obra já estava concluída e o cronograma estava sendo refeito para a conclusão da unidade quando o contrato foi rompido. Somada a essa situação, houve, também em 2014, a paralisação total da obra, na qual somente 130 colaboradores se mantiveram empregados, de outubro de 2014 a janeiro de 2015, e 3.500 trabalhadores de diversas áreas foram demitidos.

Os empresários afirmaram que a dívida deixada foi de $\mathrm{R} \$ 35$ milhões e que, se não fosse quitada, ameaçaria aumentar ainda mais o desemprego na região. Os impactos econômicos e financeiros também foram considerados, pois os trabalhadores consumiam na região e, sem emprego, também foi diminuído o poder de compra da população, afetando negativamente o comércio. Percebe-se, pois, que o declínio na UFN III gerou desestabilização em vários outros setores da região.

No ano de 2015, a comunidade empresarial de modo geral, especialmente aquelas com empreendimentos ligados à Petrobras, viveram uma forte tensão, pois a operação Lava Jato 
gerou muitas incertezas no mercado, e uma considerável imprevisibilidade às empresas ligadas ao segmento. Em março de 2015, o Jornal Valor Econômico (Ramalho, 2015) publicou que a Petrobras não poderia retomar a construção da UFN III por falta de equipamentos.

\subsection{Síntese das entrevistas}

\subsection{Ator A}

No que se refere ao declínio organizacional, esse sujeito apresentou como ideia básica a responsabilidade da Petrobras, evidenciada desde a elaboração do projeto básico. A relata a redução gradual dos recursos até ausência total por inércia da Estatal, que promoveu demissões, assim como perda aos fornecedores, com consequente paralisação do projeto organizacional UFN III. Os dados evidenciam uma associação direta e significativa entre a Petrobras e o declínio do projeto UFN III.

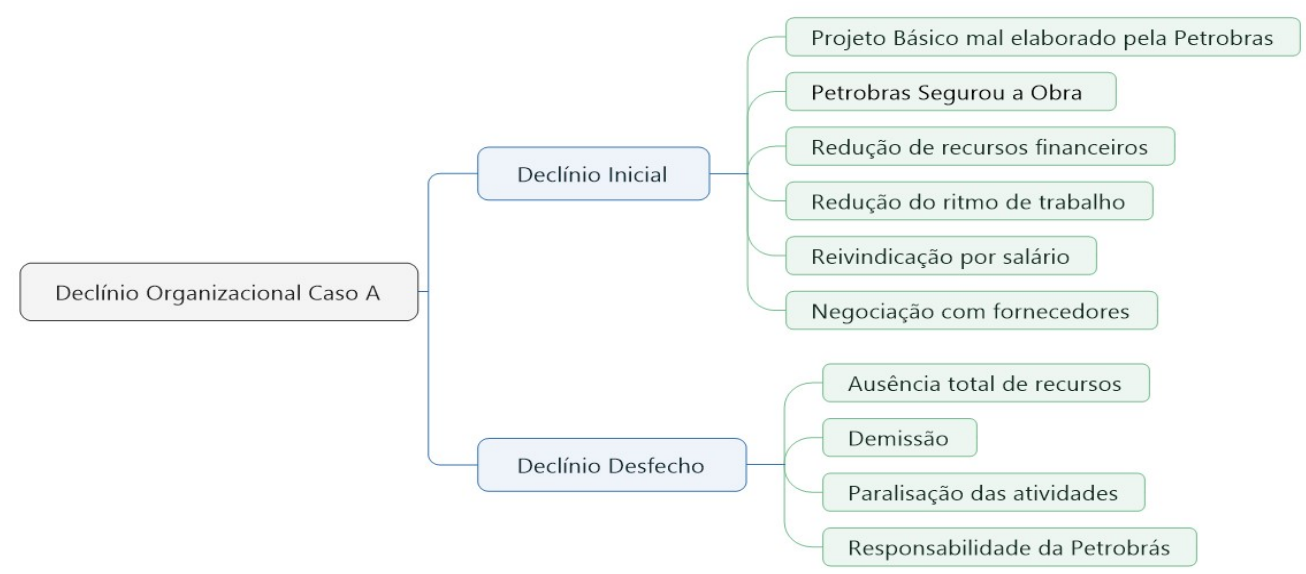

Figura 1. Esquema do declínio organizacional do ator $\mathrm{A}$

Fonte: Os autores.

\subsection{Ator B}

O declínio organizacional expresso por esse sujeito envolve a má administração de recursos, que levou à limitação financeira do projeto e originou graves problemas, como as demissões. B sugere que sob as condições de declínio os gestores do projeto encontram-se frente a uma variedade de novas situações, deparam-se com pressões pessoais e organizacionais, mas há ausência de informações e isso torna qualquer resposta difícil; assim, 
as mudanças constantes não eram comunicadas pelos gestores aos trabalhadores, com total indefinição do quadro. A noção de que a Petrobras teria tido uma conduta inesperada ao rescindir o contrato com o consórcio, atitude nunca antes vista, surge como ocasionadora do desfecho. Esse esquema tem como foco os sentimentos pessoais de medo e desorientação pela ausência de feedback e indecisão experienciada durante o período.

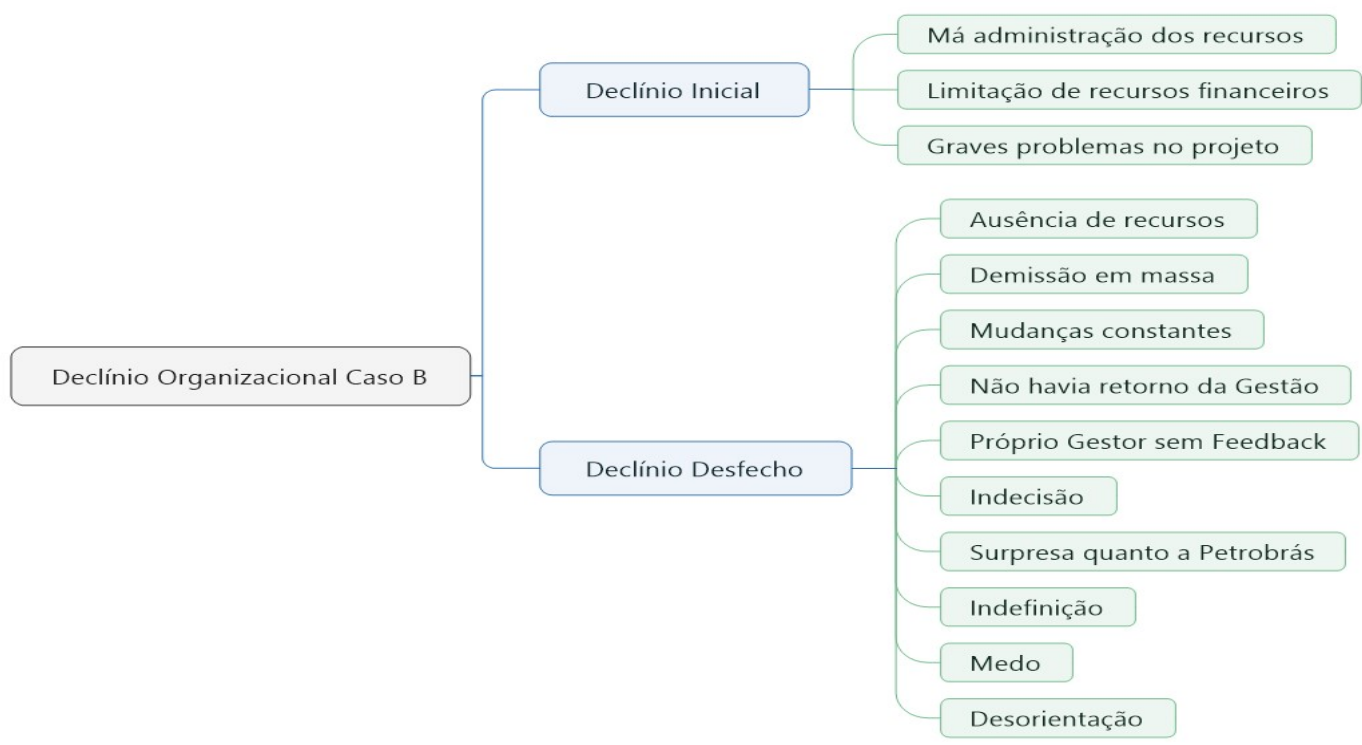

Figura 2. Esquema do declínio organizacional do ator $\mathbf{B}$ Fonte: Os autores.

\subsection{Ator C}

É interessante notar que, para esse entrevistado, na falta de planejamento e de controle associados ao gasto excessivo e superfaturamento promoveram a escassez de recursos financeiros, também surge a construtora Galvão Engenharia como alvo da operação Lava Jato, o que restringiu ainda mais as possibilidades de recuperação do declínio do projeto organizacional UFN III. A insegurança gerada pela situação provoca sentimentos de apreensão e impotência. A estrutura define ligações estratégicas entre as causas da dificuldade financeira, a má gestão, os processos ilícitos e a investigação da polícia federal nas empresas do segmento. 


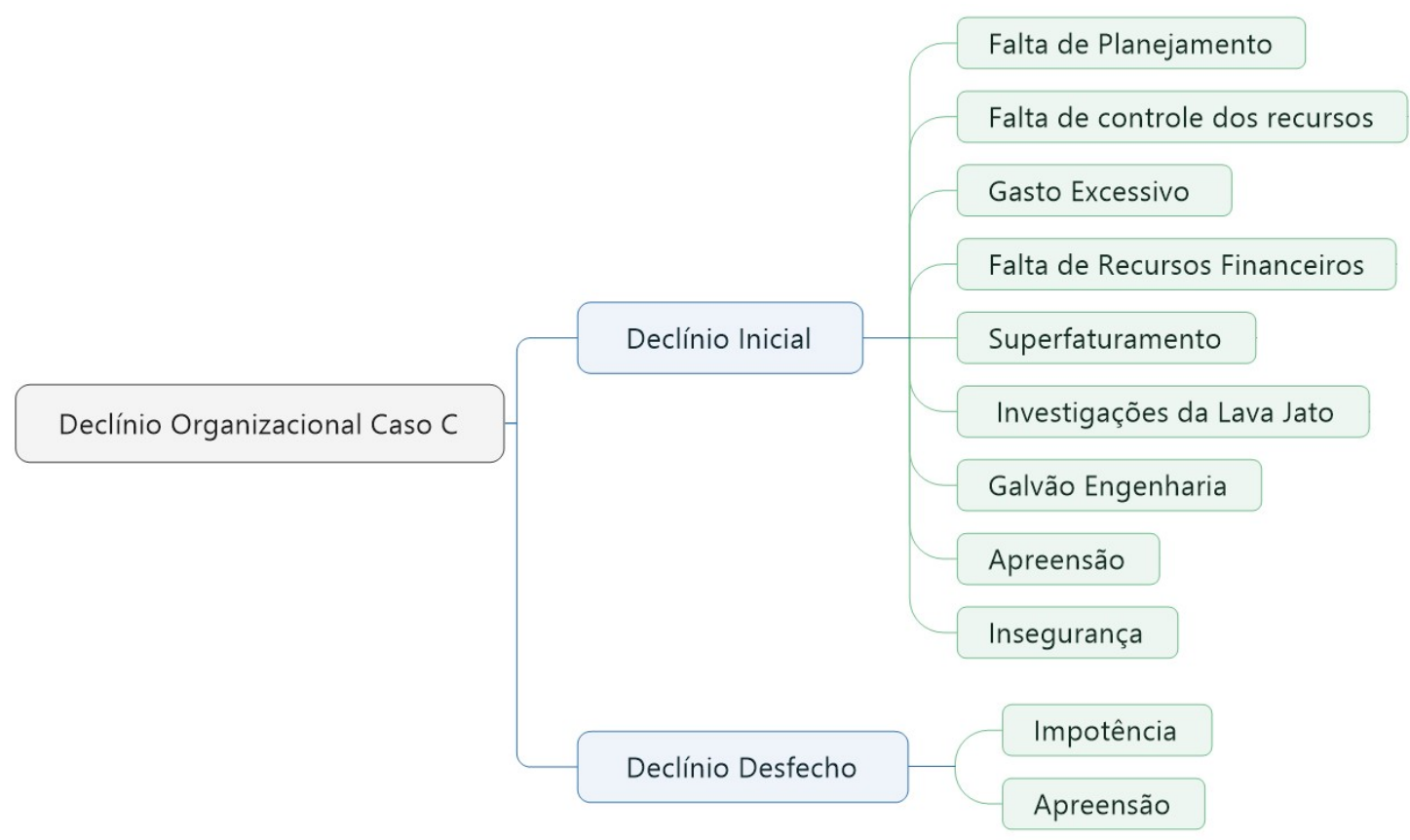

Figura 3. Esquema cognitivo de declínio organizacional do Ator C Fonte: Os autores.

\subsection{Ator D}

O conceito de declínio organizacional para essa entrevistada baseia-se no superfaturamento da obra, nos gastos indevidos e salários exorbitantes; os problemas da Petrobras com a justiça, assim como da Galvão Engenharia, levaram à diminuição de recursos e, como consequência, ao atraso de pagamentos dos salários, redução do ritmo de trabalho e demissões. A tensão já era presente até que a Petrobras definiu pela rescisão do contrato; assim, o desfecho envolve dificuldades, desemprego e tristeza. Os dados indicam que disfunções organizacionais, provenientes de processos irregulares da estatal e da empresa líder do consórcio, desencadearam a restrição de recursos e o declínio. 


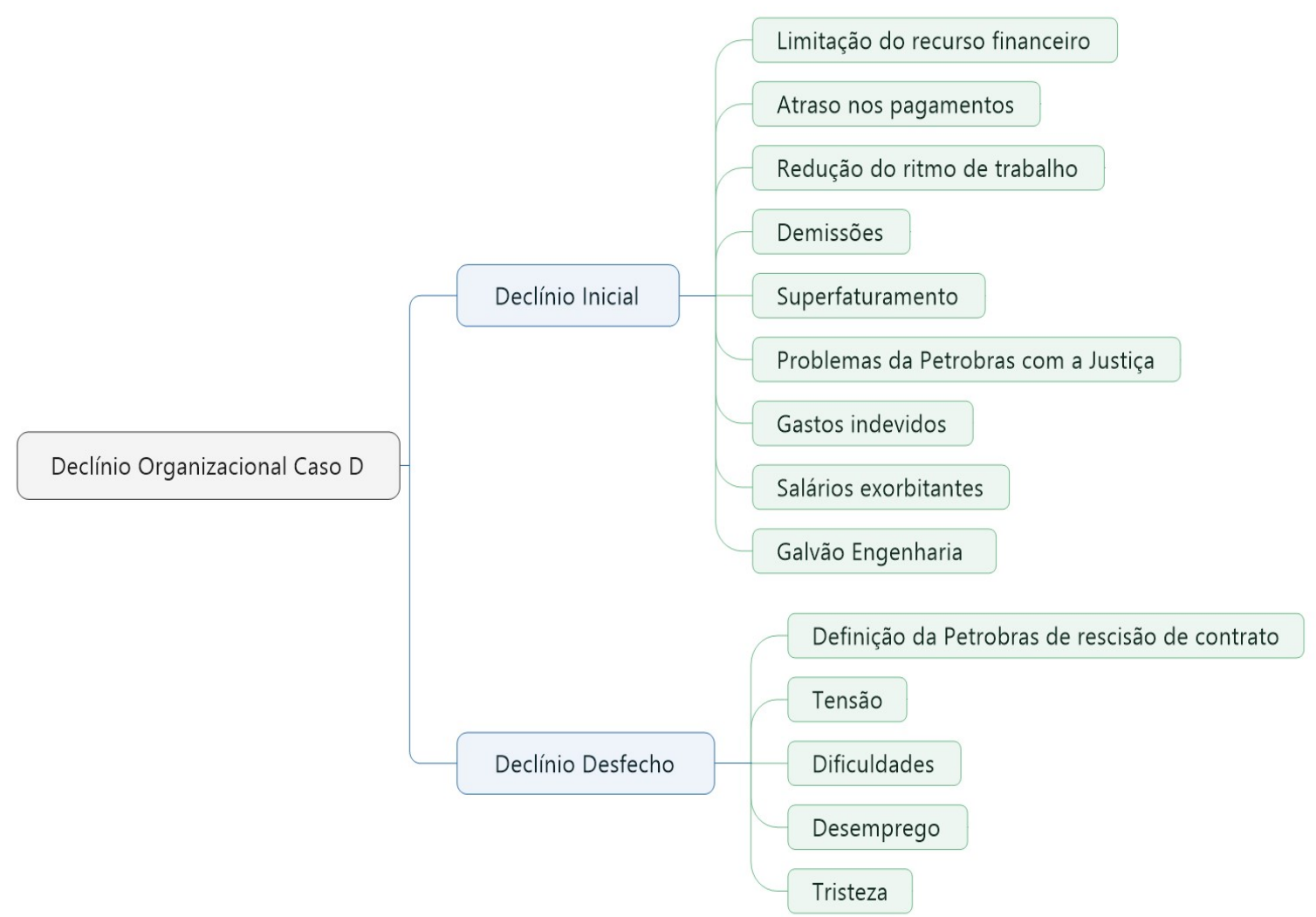

Figura 4. Esquema cognitivo de declínio organizacional do Ator D Fonte: Os autores.

\subsection{Ator $\mathbf{E}$}

No que se refere ao conceito de declínio organizacional, esse sujeito apresentou como ideias básicas: a possiblidade de greve, pela falta de pagamento dos salários, a mudança na rotina e a intervenção policial. Não existe nenhuma expressão quanto aos fatores externos à organização, embora cite a intervenção policial como uma ação focada em coibir o que estava sendo roubado dos trabalhadores. Associada à possibilidade de não receber seu salário, o entrevistado pensa em garantir seu sustento por algum tempo e, assim, solicita que o desliguem da empresa, pois demitido sem justa causa também teria um valor maior a receber. 


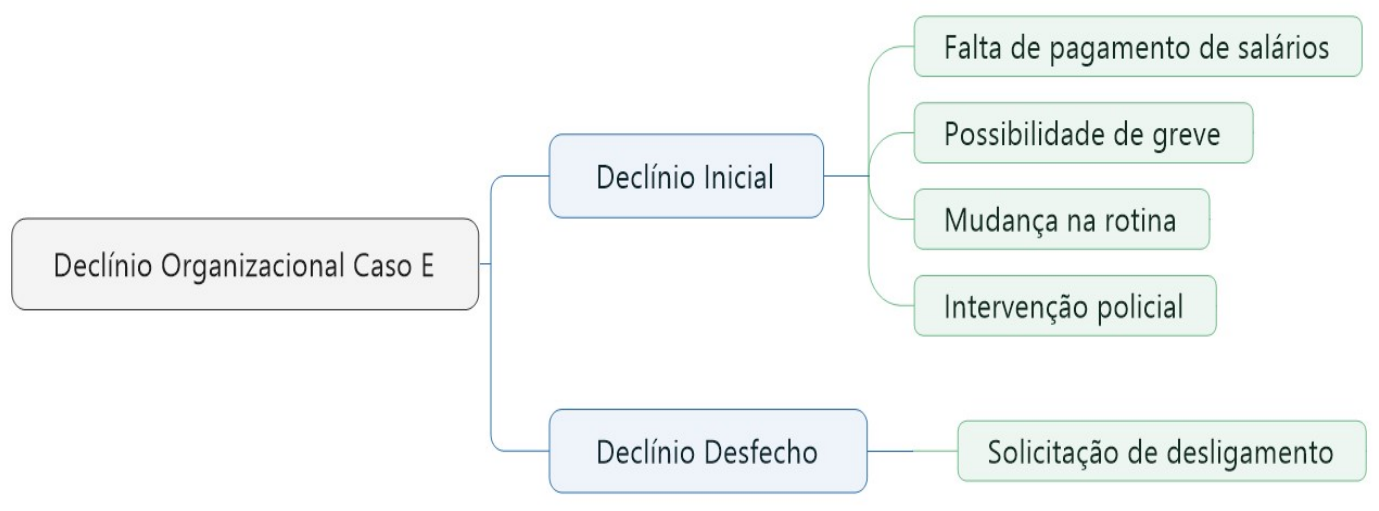

Figura 5. Esquema cognitivo de declínio organizacional do Ator E Fonte: Os autores.

\subsection{Ator $\mathbf{F}$}

Esse entrevistado apresentou em seu discurso o desvio de dinheiro realizado pela estatal; roubo que ocasionou uma intervenção policial na UFN III. Isso promoveu o corte de pessoal e a paralisação do empreendimento. A noção revelada pelo entrevistado é o declínio como consequência da corrupção existente em todos os níveis.

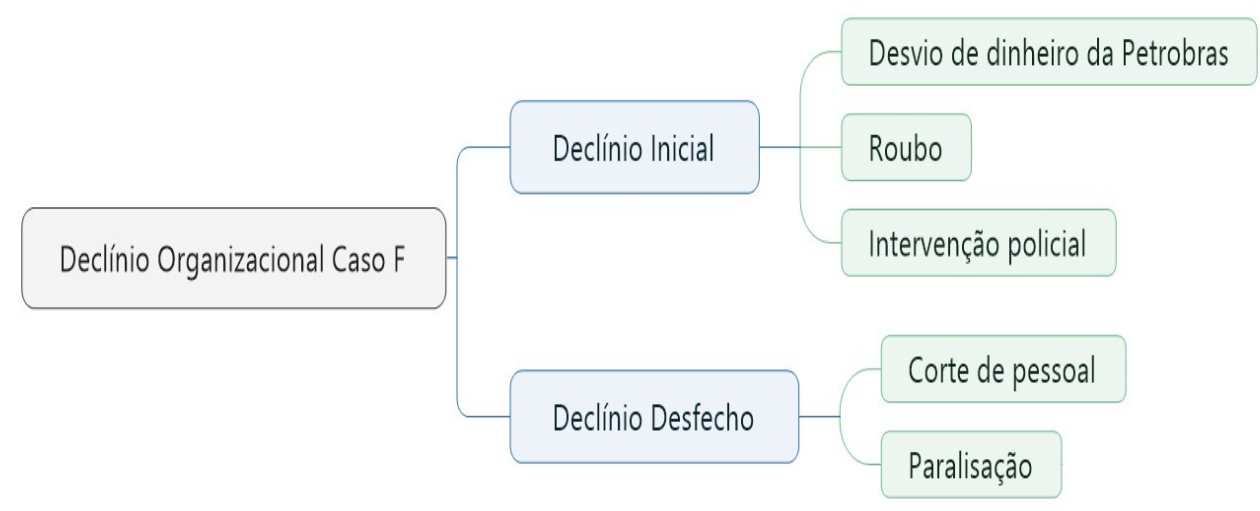

Figura 6. Esquema cognitivo de declínio organizacional do Ator F Fonte: Os autores.

\subsection{Impactos do declínio segundo os atores}

As incertezas e recorrentes mudanças sociais e organizacionais pelas quais passam o país e que, por consequência, caracterizam grande parte da vivência dos trabalhadores brasileiros nas organizações. Revelam-se como novos conhecimentos, que tendem a contribuir com a mudança dos esquemas por informações advindas de novas 
experimentações: "diversas propriedades dos esquemas são propensas a mudar com o aumento da experiência” (Borges \& Yamamoto, 2004, p. 46).

Bastos (2001), ao discorrer sobre a influência da cognição nos estudos organizacionais, apresenta vários temas emergentes, entre eles o processamento da informação em ambientes turbulentos e argumenta sobre a premência de estudos sobre a compreensão das cognições individuais e partilhadas, assim como sua influência sobre as ações. Nessa direção, é possível afirmar que este tema está longe de ser esgotado até pela dificuldade empírica de se testar diferentes proposições teóricas.

$\mathrm{Na}$ perspectiva cognitiva, especialmente utilizando os esquemas cognitivos, compreende-se a aplicabilidade dos mesmos na compreensão e interpretação dos eventos, situações e objetos. É notório que cada indivíduo possui um ciclo interno e específico que dá forma a percepção, e é modificável pela experiência, ou seja, a prática de trabalho permite a significação ao incorporarem elementos de seu conhecimento e ignorarem outros (Bartunek \& Moch, 1987).

Os atores (A, B, C, D, E, F) se expressam e associam o declínio organizacional, a falta de recursos financeiros, agrupando conteúdos mais diversificados como causas, à má administração, à falta de planejamento, às irregularidades administrativas, à corrupção das empresas que compunham o consórcio responsável pelo projeto, assim como da Petrobras, roubo e desvio de dinheiro. Verificou-se, ainda, a repercussão do fenômeno de declínio na perda de eficácia organizacional do projeto, pela ineficiência interna, com perturbações significativas no ambiente de trabalho. A tensão gerada pela insegurança do ambiente tem como base sentimentos negativos, como apreensão, tristeza, desorientação e medo, mais característico dos níveis intermediários (B, C, e D), e daqueles que permaneceram até a paralisação total do projeto.

Como alvo de atenção (E e F), descrevem uma intervenção policial, com a prisão de equipamentos e pessoas; de acordo com o discurso dos atores, esse foi o final da construção da UFN III. Os elementos que formam os esquemas nos permitem perceber quão diversa podem ser suas configurações; os atores descrevem e interpretam sua experiência no projeto UFN III com similaridades, mas também com diferenças bem demarcadas que podem ser explicadas por fatores posicionais e de escolaridade dos mesmos. A diferença está relacionada ao conteúdo dos atores alocados na produção que citam a intervenção, sendo que essa visão própria de cada um é que nos permite reconhecer as diferentes concepções sobre um mesmo fenômeno (Bastos \& Borges-Andrade, 2004). 
Analisando comparativamente, outro dado é o nível de complexidade dos esquemas; ou seja, para alguns atores (A, B, C e D), a noção de fase inicial de declínio é bem mais ampla e inclui vários indicadores frente a distintos focos e bases, como o superfaturamento, operação Lava Jato, a atuação da Petrobras, interrelacionados e apoiados em diferentes formas de sinalizar a falta de recursos financeiros. Para E e F é bem mais simples, no que se refere aos indicadores.

Embora o significado subjetivo possa ser conceituado como esquema cognitivo, pois impacta na avaliação e influencia o comportamento (Pinho \& Bastos, 2014), existem também significados comuns, sendo que o esquema cognitivo do grupo se desenvolve a partir de seus membros e dos conteúdos das estruturas de conhecimento que podem ser partilhados e denominados de esquemas semelhantes (Rentsch \& Woehr, 2004). Assim, a Figura xx abaixo apresenta conteúdos gerais identificados a partir de conceitos e ideias comuns e individuais para representar as dimensões de impacto do declínio organizacional. Sendo que a frequência dos mesmos denota sua centralidade cognitiva. Quando o conteúdo foi citado apenas uma vez, não foi colocado número entre parênteses; os demais estão enumerados. 


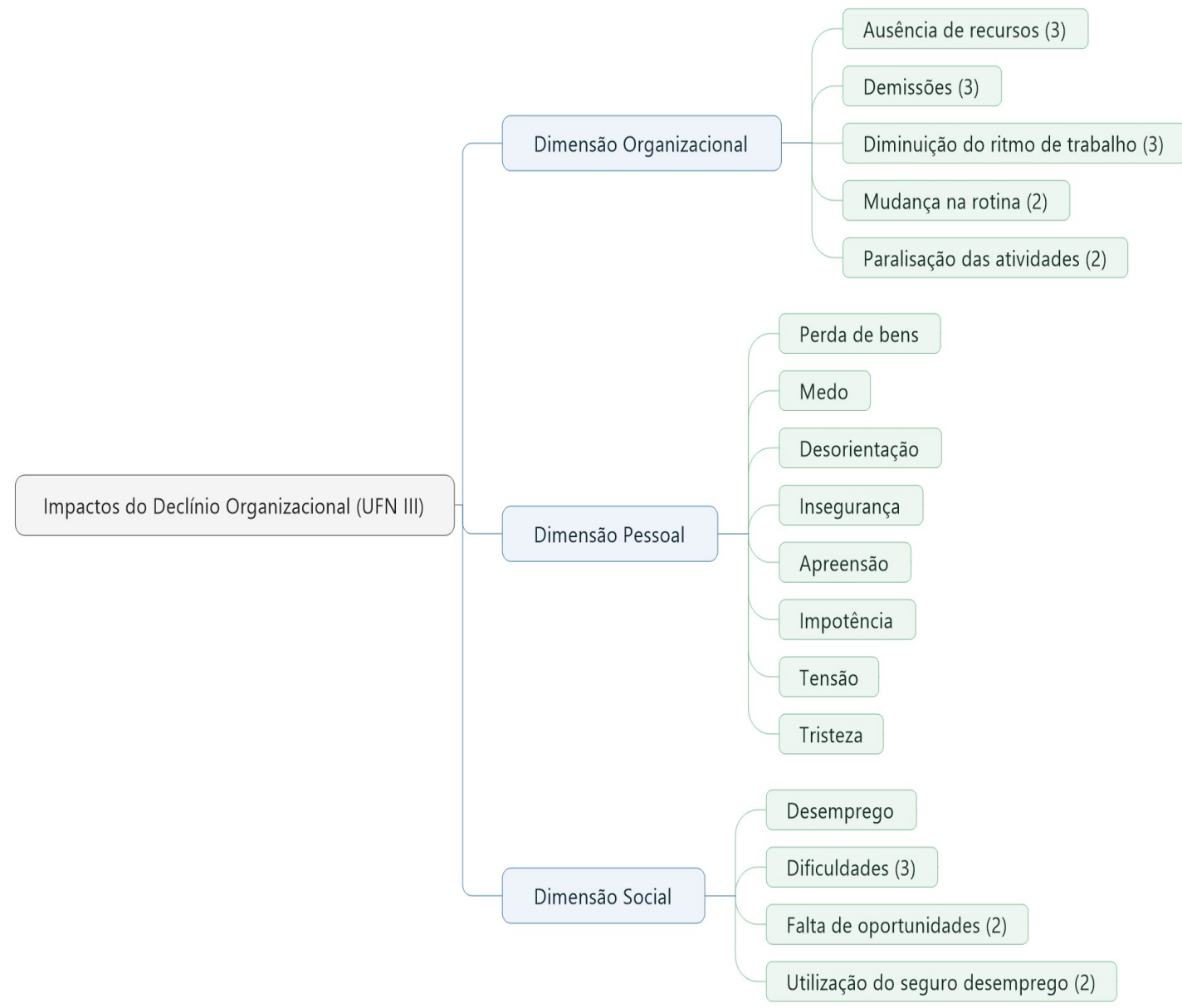

Figura 7. Impactos do declínio organizacional segundo a representação dos atores

Fonte: Os autores.

Inicialmente, dois grupos de características podem ser identificados como compartilhados pelos atores, pela frequência dos conteúdos; por sua vez, a percepção dos impactos pessoais são interrelacionados, evidenciando, assim, similaridade também em relação aos conteúdos que a compõem. Na visão de Orlikowski e Gash (1994), existe a tendência ao compartilhamento de conhecimentos, percepções e expectativas entre pessoas próximas. Já Sternberg (2000) argumenta que os esquemas abrangem uma série de conceitos interrelacionados em um ambiente significativo, que ao serem estruturadas incluem informações que podem ser aplicadas como base para interpretação de novas situações.

O impacto organizacional reconhecido pelos atores destaca a ausência de recursos financeiros, com gradual mudança na dinâmica do projeto, até a paralisação total. Esses dados corroboram com os achados de D’aveni (1989), que o declínio começa quando cessam os 
recursos e a paralisação surge como uma resposta. Assim, os recursos assumem um papel principal no processo de declínio.

O impacto no contexto social é representado pela limitação de oportunidades, a falta de vagas e o excesso de pessoas qualificadas disponíveis no mercado, assim como, a necessidade de que as pessoas modifiquem o seu sistema de vida frente as dificuldades e do desemprego. A maioria dos indivíduos não está preparada para o evento de uma demissão; a discussão sobre a perda do emprego deve ser profunda, pois é vivida como um abandono, perda da identidade, pelo significado que a falta do trabalho assume (Caldas, 1998).

Além disso, surge no discurso dos atores o conteúdo relacionado ao impacto pessoal, como influenciado pelos eventos organizacionais, o que nos leva à compreensão da influência das características e carências organizacionais nos indivíduos remanescentes nas empresas, além das consequências negativas que reverberam ou permanecem socialmente, emocionalmente e cognitivamente, corroborando com o estudo brasileiro de Caldas (1998). Destaca-se, ainda, que para os atores a perda de remuneração e a ameaça de desemprego, que ilustram o conteúdo de abalo pessoal, assim como os diferentes sentimentos externados pela indefinição da situação, a escassez da remuneração e a necessidade de redimensionamento de um novo trabalho, salientam a importância sobre a necessidade de compreender como as pessoas pensam, sentem e agem nessas circunstâncias.

Pesquisas nessa direção, como argumentam Gondim et al. (2010), podem servir para pensar comportamentos futuros frente ao mercado. Os resultados do estudo da autora, entre desempregados e empregados, demonstram que os atores empregados preocupam-se mais com a segurança, e postula que isso esteja relacionado com a preocupação de não perder o emprego. A despeito dos dados e discussões teóricas que a ameaça ao desemprego e as demissões suscitam, uma questão pertinente é considerar as mudanças ocorridas nos últimos anos no que se refere aos efeitos das reduções drásticas no quadro de empregados por declínio ou falência, entre os atores.

No que tange ao impacto pessoal, surge o medo e a insegurança, o que para Greenhalgh (1982) é característico de situação de declínio, onde há grandes possibilidades de que os indivíduos apresentem comportamentos e atitudes negativas para com a organização, bem como à redução de produtividade. Para Tway (1993 citado por Caldas, 1998), a perda da confiança na empresa talvez seja uma das consequências mais fortes. Apesar de alguns estudos avaliarem o declínio sob um foco específico e diferente desse, sabe-se que o comportamento do empregado é reflexo de múltiplos fatores, mas os conteúdos expressos corroboram aos resultados encontrados por Witte, Hooge e Vanbelle (2010) sobre as 
incertezas do período, e de Kinnunen e Nätti (1994) sobre a insegurança gerada que pode ter como efeito direto a diminuição do bem-estar psicológico, entre outras consequências negativas, e como efeitos indiretos, dificultar o planejamento e a tomada de decisão quanto às ações atuais e futuras, assim como promover a resistência à mudança, especialmente com experiências anteriores de desemprego (Heaney, Israel, \& House, 1994; Dekker \& Schaufeli, 1995).

Os esquemas influenciam a percepção, mas, para Barr, Stimpert e Huff (1992), o perceber está incrustrado no nível organizacional, e a mudança de esquemas leva tempo. Assim, pode-se também postular que esse significado atribuído ao trabalho/emprego pode atuar como fator moderador ou agravante dos efeitos do declínio. Nesse estudo, os atores expressam sentimentos negativos em relação ao período de declínio, mas relatam a certeza e a disponibilidade em retornar ao projeto e valoração positiva à sua experiência.

Além da discussão supracitada, uma outra questão importante e que pode ser destacada é que para Moscon (2009) a intenção de permanecer na organização relaciona-se ao comprometimento, no entanto, dados ainda controversos apontam que o comprometimento afetivo amortiza os efeitos dos estressores do trabalho. Em uma outra perspectiva, Caldas (1998) discute os atenuadores dos efeitos de uma situação de demissão em massa, argumentando que fatores cognitivos, organizacionais e individuais podem moderar o impacto. Para o autor, existem moderadores passivos e ativos, onde os passivos seriam aqueles já presentes na organização e ativos aqueles que a organização poderia desenvolver para amenizar os efeitos da situação. Ainda, corroborando Caldas (1998), argumenta que o significado do emprego para o indivíduo pode ser um grande moderador subdividido em dimensões pessoais, cognitivas, profissionais, organizacionais, entre outras.

Antonacopoulou e Sheaffer (2014) destacam a importância do indivíduo aprender com o fracasso, como base para a melhoria. Mas, para Labianca, Gray e Brass (2000), parece que a resistência cognitiva à mudança pode ser um grande empecilho, pois uma das principais funções do esquema é ajudar a pessoa a identificar os estímulos, que, por sua vez, fornecem proposições sobre como podem ser interpretados as situações e os planos elaborados a respeito. Assim, um dos aspectos que mais chamam a atenção quando surge a necessidade de estudo sobre fracasso organizacional e a resistência à mudança por parte do ator refere-se à complexidade de se investigar e de acessar os conteúdos que possibilitam a sua identificação. Explicita quão importante é desenvolver estratégias e instrumentos que permitam investigar o fenômeno e suas articulações de forma ainda mais precisa. 


\section{Considerações Finais}

Ao discorrer sobre a influência da cognição nos estudos organizacionais, Bastos (2001), apresenta vários temas emergentes, entre eles o processamento da informação em ambientes turbulentos e argumenta sobre a premência de estudos sobre a compreensão das cognições individuais e partilhadas, assim como sua influência sobre as ações. Nessa direção, é possível afirmar que este tema está longe de ser esgotado até pela dificuldade empírica de se testar diferentes proposições teóricas.

As incertezas e recorrentes mudanças sociais e organizacionais pelas quais passam o país e que, por consequência, caracterizam grande parte da vivência dos trabalhadores brasileiros nas organizações revelam-se como novos conhecimentos, que tendem a contribuir com a mudança dos esquemas por informações advindas de novas experimentações.

Este estudo mostrou que o declínio organizacional e a ameaça do desemprego são campos de pesquisa ainda em construção, e destaca o papel da psicologia na identificação desses espaços de estudo e intervenção. Torna-se evidente a necessidade de acompanhamento desses fenômenos, tendo o indivíduo como unidade de análise, assim como o reconhecimento de novas demandas individuais, organizacionais e psicossociais, na medida em que elas podem influenciar seus julgamentos e escolhas, questões centrais e que representam uma importante forma de enfrentamento e adaptação às mudanças. Destaca-se que as contribuições que o presente estudo traz para a compreensão do fenômeno de declínio organizacional estão circunscritas a um determinado enfoque e abordagem, ou seja, ao papel das estruturas cognitivas como influenciadores do comportamento.

\section{Referências}

Açuaña, E., \& Fernandes, F. (1995, abr./jun.). Análise de mudanças organizacionais: utilidades para políticas sociais. Revista de Administração Pública, Rio de Janeiro, 29(2), pp. 80-109.

Antonacopoulou, E. P., \& Sheaffer, Z. (2014). Learning in Crisis: Rethinking the Relationship Between Organizational Learning and Crisis Management. Journal ofManagement Inquiry, 23(1), pp. 5-21.

Barr, P. S., Stimpert, J. L., \& Huff, A. S. (1992). Cognitive change, strategic action, and organizational renewal. Strategic Management Journal, 13, p. 15-36. 
Bartunek, J. M., \& Moch, M. K. (1987, dez.). First-order, second-order, and third-order change and organizational development interventions: a cognitive approach. Journal of Applied Behavioral Science, 23(4), pp. 483-500.

Bastos, A. V. B., \& Borges-Andrade, J. E. (2004). Nota técnica: cognição e ação: o ator ocupa a cena nos estudos organizacionais. In M. Caldas, R. Fachin, \& T. Fischer (Org.), Handbook de Estudos Organizacionais (pp. 69-76). São Paulo: Atlas: 2004.

Bastos, A. V. B., \& Janissek, J. (2014). Cognição nas Organizações de Trabalho. In J. C. Zanelli, J. E., Borges-Andrade, \& Bastos, A. V. B. (Org.), Psicologia Organizações e Trabalho no Brasil (pp. 203-243). Porto Alegre: Artmed, 2014.

Bastos, A. V. B., \& Santos, M. V. (2000). O 'schema' de trabalhador comprometido: elemento definidor da identidade no trabalho. Trabalho apresentado no Xxx Reunião Anual de Psicologia, Brasília: Sociedade Brasileira de Psicologia. Resumo

Bastos, A. V. B. (2000). Mapas cognitivos: ferramentas de pesquisa e intervenção em processos organizacionais. Trabalho apresentado no Encontro Nacional De Estudos Organizacionais Da Associação Nacional Dos Programas De Pós-Graduação Em Administração, Curitiba: ANPAD. Anais.

Bastos, A. V. B. (2001). Cognição e ação nas organizações. In E. P. Davel \& S. C. Vergara (Org.), Gestão com Pessoas e Subjetividade (pp. 157-189). São Paulo: Atlas, 2001.

Bastos, A.V. B. (2002). Mapas cognitivos e a pesquisa organizacional: explorando aspectos metodológicos. Estud. Psicol., Natal, 7(spe), pp. 64-77.

Bastos, A. V. B., Souza, J. J., Costa, V. M. F., \& Peixoto, A. L. A. (2011). A Adoção de Novas Práticas de Gestão: explorando o esquema cognitivo dos atores em empresas com diferentes padrões de inovação. Revista de Ciências da Administração, Florianópolis, 13(31), pp. 243-278.

Bastos, A. V. B, Loiola, E., Queiroz, N. S., \& Silva, T. D. (2014). Conceito e Perspectivas do estudo das Organizações. In J. C. Zanelli, J. E. Borges-Andrade, \& A. V. B. Bastos (Org.), Psicologia Organizações e Trabalho no Brasil (pp.73-108). Porto Alegre: Artmed.

Borges, L. O., \& Yamamoto, O. H. (2004). O mundo do trabalho. In J. C. Zanelli, J. E. Borges-Andrade, \& A. V. B. Bastos (Org.), Psicologia Organizações e Trabalho no Brasil (pp. 24-62). São Paulo: Artmed.

Brasil. [2007?]a. Ministério do Planejamento. Sobre o PAC. Brasil: Ministério do Planejamento. Recuperado de: http://www.pac.gov.br/sobre-o-pac 
Brasil. [2007?]b. Ministério do Planejamento. Petróleo e Gás Natural. Mato Grosso do Sul: Ministério do Planejamento. Recuperado de: http://www.pac.gov.br/infraestruturaenergetica/petroleo-e-gas-natural/ms

Breakwell, G. M. et al. (2010). Métodos de pesquisa em Psicologia (F. R. Elizalde Trad.). Porto Alegre: Artmed.

Cantero, D. S. M. (2014). Teoría fundamentada y Atlas.ti: recursos metodológicos para la investigación educativa. Revista Electrónica de Investigación Educativa, 16(1), pp. 104122.

Caldas, M. P. (1998). Demissão, plural e singular: um estudo sobre enxugamentos de pessoal no nível organizacional e sobre perda de emprego no nível individual. (Tese Doutorado em Administração, Escola de Administração de Empresas de São Paulo, Fundação Getúlio Vargas, São Paulo).

D'Aveni, R. A. (1989). The Aftermath of Organizational Decline: a longitudinal study of the strategic and managerial characteristics of declining firms. The Academy of Management Journal, 32(3), pp. 577-605.

Dekker, S. W. A., \& Schaufeli, W. B. (1995). The Effects of Job Insecurity on Psychological Health and Withdrawal: A Longitudinal Study. Australian Psychologist, 30, pp. 57-63.

Fiol, C. M., \& Huff, A. S. (1992, may). Maps for managers: where are we? Where do we go from here? Journal of Management Studies, 29(3), pp. 267-285.

Fonseca, V. S., \& Machado-da-Silva, C. L. (2010, set.). Conversação entre abordagens da estratégia em organizações: escolha estratégica, cognição e instituição. Rev. adm. contemp., Curitiba, 14(spe), pp. 51-75. Recuperado de: http://www.scielo.br/scielo.php?script=sci_arttext\&pid=S1984-92302002000300006

Gil, A. C. (1987). Métodos e técnicas de pesquisa social. São Paulo: Atlas.

Gondim, S. M. G. et al. (2010, dez.) Atribuições de causas ao desemprego e valores pessoais. Estud. psicol. (Natal), 15(3), pp. 309-317.

Greenhalgh, L. (1982). Maintaining organizational effectiveness during organizational retrenchment. Journal of Applied Behavioral Science, 18, pp. 155-170.

Heaney, C. A., Israel, B. A., House, J. S. (1994, may). Chronic job insecurity among automobile workers: effects on job satisfaction and health. Social science \& medicine, 38(10), pp. 1431-1437.

Hodgkinson, G. P., \& Healey, M. P. (2008). Cognition in organization. Annual Review of Psychology, 59, pp. 387-417. 
Jordão, F. (1998). Uma Abordagem Cognitiva das Organizações: estudo do mapeamento cognitivo na banca portuguesa. (Tese de Doutorado em Psicologia, Faculdade de Psicologia e Ciências da Educação, Universidade do Porto, Porto, Portugal).

Lester, L. D., Parnell, J. A., \& Carraher, S. (2003). Organizational life cycle: a five-stage empirical scale. The International Journal of Organizational Analysis. 11(4), pp. 339354.

Labianca, G., Gray, B., \& Brass, D. J. (2000). A Grounded Model of Organizational Schema Change During Empowerment. Organization Science, 11(2), pp. 235-57.

Machado-da-Silva, C. L., Fonseca, V. S., \& Fernandes, B. H. R. (1999). Mudança e estratégia nas organizações: perspectivas cognitiva e institucional. In M. M. F. Vieira \& L. M. B. de Oliveira (Org.), Administração contemporânea: perspectivas estratégicas (pp. Xx-xx). São Paulo: Atlas.

Martins, C. (2013, 27 de abril). Fábrica de Três Lagoas reduzirá em 40\% compra de fertilizantes pelo Brasil. Campo Grande News [Online], Campo Grande, MS. Recuperado de: https://www.campograndenews.com.br/economia/fabrica-de-tres-lagoas-reduzira-em40-compra-de-fertilizante-pelo-brasil

Montello, D. R. (2002). Cognitive map-design research in the twentieth century: Theoretical and empirical approaches. Cartography and Geographic Information Science, 29(3), pp. 283-304.

Moscon, D. C. B. (2009). Teorias implícitas de trabalhador comprometido e estratégias cotidianas de gestão: uma análise qualitativa. (Dissertação de Mestrado em Administração Núcleo de Pós-Graduação em Administração da Escola de Administração, Universidade Federal da Bahia, Salvador).

Kinnunen, U., \& Nätti, J. (1994). Job insecurity in Finland: Antecedents and consequences. European work and organizational psychologist, 4(3), pp. 297-321.

Orlikowski, W. J. \& Gash, D. C. (1994, abr.).Technological frames: making sense of information technology in organizations. ACM Transactions on Information Systems, 12(2), pp. 174-207

Pinho, A. P. M, \& Bastos, A. V. B. (2014). Vínculos do trabalhador com a organização: comprometimento, entrincheiramento e consentimento. São Paulo: Hucitec.

Pupo, F. (2014, 19 dez.). Petrobrás rescinde contrato em Unidade de Fertilizantes em MS. Valor Econômico [Online], São Paulo. Recuperado de: https://www.valor.com.br/agro/3831380/petrobras-rescinde-contrato-em-unidade-defertilizantes-em-ms 
Ramalho, A. (2015, 19 mar.). Justiça autoriza Petrobras a recuperar R\$ 471 milhões em equipamentos. Valor Econômico [Online], Rio de Janeiro, RJ. Recuperado de: https://www.valor.com.br/empresas/3964844/justica-autoriza-petrobras-recuperar-r-471milhoes-em-equipamentos

Rentsch J. R., \& Woehr, D. J. (2004). Quantifying congruence in cognition: social relations modeling and team member schema similarity. In E. Salas \& S. M. Fiore (Ed.), Team Cognition: Understanding the Factors that Drive Process and Performance (pp. 11-31). Washington, DC: American Psychological Association.

Ribeiro, J. C. (2014, jul.). A construção da UFN III em Três Lagoas-MS: no rastro do fetiche da terra de gigantes. Revista Pegada, 15(1), pp. 208-225. Recuperado de: http://revista.fct.unesp.br/index.php/pegada/article/view/2574/2629

Rios, M. C., Lula, A. M., Amaral, N. A., \& Bastos, A. V. B. (2009). Contratos Psicológicos e Comprometimento: o mapeamento cognitivo dos construtos junto a profissionais de RH. Acta Científica, 1(16), pp. 9-24.

Salles, L. F. (2015). Como as empresas brasileiras da indústria têxtil lidam com o declínio? Um estudo multicaso das ações estratégicas. Dissertação de Mestrado em Administração, Universidade Nove de Julho, São Paulo.

Serra, F., Ferreira, M., \& Almeida, M. (2013). Organizational decline: a yet largely neglected topic in organizacional studies. Managemente Research, 11(2), pp. 133-156.

Souza, J. J. (2007). Teoria implícita de organização inovadora em empresas com padrões diferenciados de adoção de práticas de gestão. Tese de Doutorado em Administração, Núcleo De Pós-Graduação em Administração, Universidade Federal da Bahia, Salvador.

Sternberg, R. J. (2000). Psicologia cognitiva. Porto Alegre: Artes Médicas.

Tanure, B., Evans, P., \& Pucik, V. (2007). Virtudes e pecados capitais: a gestão de pessoas no Brasil. Rio de Janeiro: Elsevier.

Vicente, J. M. (2013, 10 jun.). Trabalhadores da UFN-3 declaram estado de greve. Hoje Mais [Online], Três Lagoas, MS. Recuperado de: https://www.hojemais.com.br/treslagoas/noticia/politica/trabalhadores-da-ufn3-declaram-estado-de-greve

Walter, S. A., \& Bach, T. M. (2015, abr./mai./jun.). Adeus papel, marca-textos, tesoura e cola: inovando o processo de análise de conteúdo por meio do ATLAS.TI. Rev. Administração: ensino e pesquisa, Rio de Janeiro, 16(2), pp. 275-308.

Wellman, B. Computer Networks As Social Networks. (2001). Science, 293, pp. 2031-2034.

Wildman, J. L., Salas, E., \& Scott, C. P. R. (2013). Measuring Cognition in Teams: A CrossDomain Review. Human Factors, 20(10), pp. 1-31, 2013.

Revista de Gestão e Secretariado (GeSec), São Paulo, SP, 11(2), maio/ago., 2020, p. 139-163. 
Witte, H., Hooge, J., \& Vanbelle, E. (2010). Do the long-term unemployed adapt to unemployment. Romanian Journal of Applied Psychology, 12(1), pp. 8-14.

Submetido em: 27.06.2019

Aceito em: $\quad 22.07 .2019$ 